\title{
The Finnish Poet Pentti Saarikoski (1937-1983)
}

\author{
Amar Annus \\ University of Tartu, Estonia
}

\begin{abstract}
The poet Pentti Saarikoski (1937-1983) was one of the most significant Finnish writers of the 20th century. He was also a prolific translator, who received many prestigious awards for his literary production. Throughout his life Saarikoski showed evidence of a certain psychopathology and mental complications for which he was twice hospitalized. The paper argues that Saarikoski possessed a large number of autistic traits and elevated symptomatology of ADHD. The traits of these conditions are often found in persons with high creative achievement. The works of the psychiatrist Michael Fitzgerald provide the theoretical background, on which the biographic evidence from Saarikoski's childhood and adult life is analyzed. The identity diffusion under which the poet suffered can be shown as beneficial to this level of creativity. Saarikoski was an autistic writer, who visualized his poetry which eventually provided him with artistic identity. In addition to autistic traits and high intelligence, Saarikoski also sought novelty and sensation, which can be attributed to his ADHD traits.
\end{abstract}

The poet Pentti Saarikoski became one of the most important Finnish writers when in 1958 his first poetry collection was published. He was also the brilliant and productive translator of about 70 works, which made an enduring contribution to Finnish literary culture. He is the only person in history who has translated both J. Joyce's Ulysses and Homer's Odyssey into a third language. He was born on
September $2^{\text {nd }} 1937$ in Impilahti, Karelia. His father Simo Saarikoski was a civil servant and journalist. His mother Elli Saarikoski was the daughter of a baker. The family had four children - his elder brother Simo and two younger daughters, Sirkka and Inkeri. During his short and intensive life, Saarikoski married four times and became the father of five children. He was a well-known person in Finnish culture, occasionally 
an active participant in public life. He received many prestigious awards for his literary works and translations.

There is enormous quantity of biographic information available about Pentti Saarikoski. His life story is taken together into two voluminous monographs (Tarkka, 1996; 2003). Saarikoski's youth diaries from 1956 to 1959 offer valuable information about poet's early self-understanding (Saarikoski, 2012). The memories of his sister Sirkka provide some interesting details concerning his developmental history (Garam, 1987). In addition, there are three published reminiscences of him by his spouses (Saarikoski, 2015; Varis, 1994; Berner 1986).

From time to time throughout his life Pentti Saarikoski showed evidence of a certain psychopathology. This is in accordance with the hypothesis that generally applies across a large group of the individuals with high creative achievement, which associates them positively with psychopathology (Schuldberg, 2001; Becker, 2001; Simonton, 2014). In school Saarikoski's impulsiveness caused the conduct problems of which the most severe case was a physical attack on his teacher of gymnastics. After this incident in 1953 Saarikoski was ostracized from the school community for some time (Tarkka, 1996). Later the mental health problems caused Saarikoski's temporary hospitalizations in 1962 and 1968. At the age of 25, he was treated in Turku Kupittaa hospital's psychiatric department. Saarikoski's doctor gave him the diagnoses Persona immatura "immature person" and Alcoholismus acutus "acute alcoholism" (Tarkka, 1996). During the episode in 1968 he was treated for three weeks at the Hesperia Clinic in Helsinki. This hospitalization took place after Saarikoski had gone through the state of delirium and a series of epileptic fits. The poet had suffered from epileptic seizures since 1966 (Tarkka, 2003). In Hesperia Clinic he received diagnoses related to alcoholism like dipsomania recurrens (Varis, 1994). The main diagnosis in 1968 was Epilepsia symptomatica (Tarkka, 2003). These diagnoses were accurate according to the medical knowledge of the time and confirm the presence of the mental complications under which the poet suffered.

This paper will argue that Saarikoski's personality possessed a large number of traits related to Autism Spectrum Condition (ASC) and elevated symptomatology of Attention Deficit and Hyperactivity Disorder (ADHD). According to recent studies these two disabilities are often found in persons with high creativity (Fitzgerald, 2005; 2008; 2014; 2015). Autism spectrum is often comorbid with ADHD in children, which points to a shared genetic risk for both conditions (Rommelse, Franke, Geurts, Hartman, \& Buitelaar, 2010). Moreover, the elevated traits of ASC and ADHD in Saarikoski's personality can explain his excessive use of alcohol. The complications from substance abuse and epilepsy caused his early death at the age of 45 . His addiction to substances was inherited from his father, who periodically indulged in drinking bouts several times in year (Tarkka, 1996). However, Saarikoski's dependence of ethanol must be viewed in the context of his inherited traits of ADHD and ASC. A recent population-based cohort study showed a doubled risk of substance use related problems in ASC and the highest risk among the individuals with ASC and comorbid ADHD (Butwicka et al., 2017). Saarikoski belonged to the latter group of highest risk, which explains his excesses in substance abuse. However, the same traits in his persona enhanced his extraordinary creativity.

\section{The "Asperger genius" Pentti Saarikoski}

In their book Unstoppable Brilliance, the medical experts A. Walker and M. Fitzgerald (2006) described the life histories of nine notable people from Ireland's past, among them the writers Pearse, Yeats, Joyce, and Beckett. If they lived today, all these persons would be diagnosed with Asperger's syndrome. The authors 
asserted that this condition is the key to genius in all ages and cultures that often predicts exceptional achievement (Walker, \& Fitzgerald, 2006). The medical label of Asperger's syndrome was not available during Saarikoski's lifetime: the first diagnosis in Finland was made in 1989 (Nieminen-von Wendt, 2004). However, the biographic evidence indicates that Saarikoski had the mild form of autism, which is synonymous with the syndrome.

According to the Irish autism expert Michael Fitzgerald, for creativity of genius proportions an IQ score over 120 is needed in addition to ASC (Fitzgerald, 2011). There is a consistent positive genetic correlation between autism and different measures of cognition, which stands in contrast to other psychiatric conditions (Warrier, 2018). As the Finnish example of "Asperger genius" Pentti Saarikoski fulfils Fitzgerald's two criteria. Saarikoski was precocious and overly talented during his schooldays and entered the University of Helsinki at the age of only 16. In the last years of his life, he credibly claimed to know 13 or 14 languages at a good level (Garam, 1987). He possessed savant-like abilities, but his academic success was meagre due to his ADHD traits. The indication of Saarikoski's autism is the fact that he did not speak until the age of three years (Garam, 1987). He occasionally suffered from epileptic fits in his adult life (Tarkka, 2003). Epilepsy is highly comorbid with autism (Baron-Cohen, 2008). His autistic traits will be fully addressed below.

Fitzgerald has pointed to ADHD as a neurological source of creativity $(2008 ; 2014)$. According to him, features of attention deficit disorder are very common in great creators, who possess less linear thinking and therefore allow all kinds of ideas to float into their mind. People with ADHD possess highly divergent thinking that can be all "over the place", which allows unusual linkages to be made (Fitzgerald, 2015, p. xxiv). The ADHD traits are applicable to Saarikoski who failed to achieve academically due to his concentration problems. His attention span was short in matters in which he was not interested. He was not interested in academic career. His nonlinear thinking style made him into a natural poet (Saarikoski, 2012). He studied literature and ancient Greek at the University of Helsinki, but never received a degree. According to his first wife, he had insurmountable anxiety of exams. After he walked away from his first examination he could not go to any further ones (Saarikoski, 2015). High anxiety often co-occurs with both ASC and ADHD. In his youth diaries he explicitly stated that he is not capable of academic achievement because of poor concentration: "I can't focus on anything for a long time, distress and the tireless spirit of a searcher pull me right away from my action ... I fly from blossom to blossom unceasingly" (Saarikoski, 2012, p. 171). He had an inattentive temperament of the dreamer, who could not work according to plans and goals (Saarikoski, 2012). The symptoms of inattention, disorganization and poor academic performance relative to ability can be explained with his ADHD traits (Willer, 2017).

There are many contradictions in Saarikoski's nature, of which he was aware. These contradictions can be partly attributed to the conflicting features of autistic and ADHD traits. He was a very shy person who nevertheless had the powerful drive to perform to others (Garam, 1987). He was good in imitating others, a capacity which is often hyperdeveloped in autism (Fitzgerald, 2018). Throughout his life he liked to be at the center of attention and even considered the career of an actor in his adolescence (Saarikoski, 2012). Persons with ADHD characteristics like to be onstage (Fitzgerald, 2008).

Saarikoski's other ambiguity was his need for both solitude and human company which "is certainly dominant in the Asperger genius" (Walker, \& Fitzgerald, 2006, p. 307). Saarikoski reported a profound sense of loneliness throughout his life. This was due to his autistic deficiency in the sense of social relatedness. The feeling of loneliness motivated his search for the company of others, but he failed to enjoy social gatherings without consuming alcohol. He often used to work in cafeterias and restaurants 
where he spent entire days (Varis, 1994). He had few intimate friends but hundreds of superficial acquaintances which is typical of an Asperger genius (Walker, \& Fitzgerald, 2006).

Autism is negatively correlated with family relationship satisfaction and friendship satisfaction (Warrier, 2018). In his youth diaries Saarikoski confessed to feelings of loneliness and strangeness even in the company of friends. He described his life as consisting of constant back and forth escapes into solitude and out of loneliness (Saarikoski, 2012). The inner conflict built up a vicious circle, which he was unable to break away from. He wrote: "I have to be alone if I want to live. But without friends I cannot live. There is no escape from this vicious circle" (Saarikoski, 2012, p. 150). From the age of 21 years Saarikoski began drinking a fair amount of alcohol every day to fight his depression and to help him socialize. At the age of 25 his daily doses increased as he started drinking from the early hours. In the same year 1962 he extensively socialized which resulted in his mental breakdown and hospitalization in Turku. The poet himself expressed concerns about his uncontrollable use of alcohol, but apparently could not do much about it. However, he was able to keep shorter periods of abstinence later in his life (Tarkka, 1996, 2003).

Various studies have found that "openness to experience" is a very important personality trait for creativity (Dollinger et al., 2004; Beaussart et al., 2014). Both high functioning autistic and ADHD persons show a fascination with novel ideas. The novelty seeking is a critical characteristic for creativity and persons with ADHD tend to be high in it (Fitzgerald, 2008). Pentti Saarikoski was a novelty and sensation seeker, which characteristics contributed to his creativity. His third wife wrote that Saarikoski needed his everyday routine but went out of the way when it had lasted for too long. According to his philosophy life had to be unpredictable, full of exceptional situations and moving towards unknowable. He much appreciated home comfort, but often disappeared to his own ways for several days (Varis, 1994). The psychological measure of "sensation seeking" contains the subscale of "disinhibition, which involves seeking sensation through social activities, promiscuity, alcohol, and drug abuse etc." (Fitzgerald, 2008, p. 8). These components of disinhibition prominently featured in Saarikoski's behavior except for the use of illegal substances.

\section{Pentti Saarikoski's Childhood}

Saarikoski's parents Simo and Elli met and married in Finnish Karelia, where they worked at the same office of a cellulose plant in Pitkäranta. In the summer 1939 the family moved to Helsinki and on the 30th November of the same year the Winter War broke out between the Soviet Union and Finland. Simo Saarikoski was commanded to war and Elli with children travelled to Norrköping in Sweden to be the guests of a distant relative of the family in March 1940. During the Winter War and Continuation War the family moved several times between Finland and Sweden until they finally settled in Helsinki in 1947.

The childhood accounts of Pentti Saarikoski point out both his sensitive and unruly nature. At the age of nine months he was a kind, quiet and easy child. In letters to his father the mother complained about Pentti's quietness with the concern, "Does he have intellectual gifts at all when he does not speak?" (Tarkka, 1996). According to his sister, Pentti did not speak until the age of three years, when he suddenly began to formulate long, clear and flowing sentences (Garam, 1987). His language and speech development was delayed although he could be occasionally very loud. Throughout his childhood, Saarikoski remained a serious, closed, silent boy and a solitary thinker (Tarkka, 1996). At the age of 18 he retrospectively characterized himself: "I was a delicate child and often wept ... even now I often want to escape from people's gaze into a dark hole" (Saarikoski 2012, p. 384). After entering university, he became a more 
socially active and energetic person, but retained his love for solitude. He explained his self-imposed social seclusion: "I don't hate people, but I love solitude" (ibid, p. 390). The traits such as preference for solitude and the delay of language are indications of autism (Baron-Cohen, 2008).

Saarikoski started school in Sweden, where he received the nickname Molotov after the prominent Soviet politician, because he never smiled at others and responded to all kinds of proposals "Nej" ("No"). Various accounts paint a picture of an isolated child, whose desire for social engagement was very limited. He went to school weeping and the process started to smooth out only when a girl classmate began to pick him up from home every morning (Garam, 1987). When the family settled in Helsinki, the 10 year old boy began his habit of going on solitary walks on the city streets for several hours. The mother became exasperated and wanted to know the whereabouts of these long absences from home, but the boy refused to explain anything. The reasons for these long walks were the need to be alone and the ADHD related trait of restlessness. Whenever possible Pentti isolated himself in his bedroom (Garam, 1987). In his childhood home he shared the bedroom with his brother, which did not satisfy his need for solitude. Although the relationship between the brothers was friendly, there are accounts of how he built a barricade of bookcases between two beds to create more privacy for himself. Saarikoski was sensitive to sounds, which explains his angry shouts at his brother on the other bed "Don't breath!" (Garam, 1987). Sensory sensitivity to sounds, smells and touch is another facet of autism (Baron-Cohen, 2008). Autistic children can be hypersensitive to other people's noise but can tolerate the same noise when they create it themselves (Fitzgerald, 2018).

Saarikoski was a restless and impulsive person, who could not stay in one place for long. In his own words, "I feel at home only when being en route" (Tarkka, 1996, p. 47). This is a facet of restlessness, which can be attributed to his ADHD traits (Fitzgerald, 2008).
The permanent feeling of restlessness is well expressed in the following quote:

I have to be in motion, move quickly from one place to another, otherwise I will become restless. I feel myself best on vehicles, on a bus, train, boat, or airplane. If I were rich, I would always travel, I would not stay anywhere for any length of time. If the environment changes all the time, I feel as if I'm at home (Tarkka, 1996, p. 416).

During his childhood Saarikoski constructed a niche of privacy in his domestic life. He did not participate in the family's activities, assuming the role of an idle boy. In an adult letter to his sister he remembers of having never cleaned his room neither washed his garments nor dishes (Garam, 1987). This kind of disability is a deficit of the executive function affiliated to the ADHD traits (Fitzgerald, 2008). Severe inability in practical matters permeated his life to the end. Despite his limited capacity to maintain romantic relationships he always needed a woman to do practical things for him and could not live a single day without help with cleaning, cooking, banking etc. (Varis, 1994). An inability to manage practical life is a hallmark of "Asperger genius" (Walker, \& Fitzgerald, 2006).

From early on there are accounts about Saarikoski's food intake problems, which can be used as the evidence for his ASC (Tarkka, 1996; Attwood, 2007). The poet retained low body weight for his entire life, which became a precarious combination with his alcohol consummation habits. His third wife well understood the health risk and supported him with a special diet (Varis, 1994). During his hospitalization period in 1968 his body weight increased from 57 to 62 kilograms, which significantly improved his health (Tarkka, 2003). The food avoidance and selective eating have a sensory basis in autism (Fitzgerald, 2018). 


\section{Pentti Saarikoski's Quest for Himself}

For several periods in his life Saarikoski wrote diaries, many of which have been published. The diaries from his young age were written during 1953-1957, when he was 16 to 20 years old (Saarikoski, 2012). During this time the young poet much reflected upon his relationship to religion, fellow human beings and himself. The main theme in these diaries is the search for self. The questions "Who am I?" and "What am I?" resound on the pages of diaries in many variations (Saarikoski, 2012). According to the later recollection, Saarikoski began writing diaries at the age of 13 with the incentive to answer the question "Who am I and of what kind, and what is the reason?" (Saarikoski, 2012, p. 380). The intense occupation in this matter reveals his identity diffusion, which has a neurological basis. People with autism have a weak sense of personal self (Fitzgerald, 2018).

According to Fitzgerald, for great creativity in arts, a degree of identity diffusion is very necessary. In the arts identity is not a fixed construct, because there is no ultimate reality in the fictional world. The artist starts the creative process with a diffuse identity and the art is an attempt to find something real, to heal his/her own identity diffusion. During the process of this search, much creative work is accomplished. Meanwhile, masks and stage identifications become a substitute for a real personality (Fitzgerald, 2015). For a creative person with identity diffusion this fixed construct of the self is achieved only temporarily:

The great artist starts out with a diffuse identity and his art is an attempt to find something real, an attempt to heal his own identity diffusion. If the great artist started out with a clear personal identity, it would be impossible for him to become a great artist (Fitzgerald, 2015, p. xxvi).

The persons with high creative capabilities are constantly searching for an authentic sense of self, but because of their brain wiring they never achieve it as a permanent condition - they tend to have only a partial identity and little self-knowledge (Fitzgerald, 2015). The corresponding autistic trait in the social domain is "lack of self-awareness" (Baron-Cohen, 2008, p. 79). Autistic persons may be aware of their identity diffusion and reflect upon it to find a solution. This was prominently the case with Saarikoski, who admitted that "I am a bigger mystery to myself than to others" (Saarikoski, 2012, p. 277). Sometimes he felt that he is an odd person, a stranger or an animal because the powers driving his spirit seemed so inexplicable. This was especially sensed when encountering other human beings. He claimed to be the spirit searching for the unusual and interested in everything abnormal. He complained about his perverse imagination and abnormal sexuality and wondered whether he might be homosexual. He did not like himself and wanted to be a normal human being (Saarikoski, 2012). Unusual sexual interests can be a part of autistic personality (Fitzgerald, 2018). Here Saarikoski exemplifies the autistic identity diffusion and dissatisfaction with himself, which motivated a creative healing process. Fitzgerald has written about fragmented sense of self that is often found in artistic creativity:

Identity diffusion or a fragmented sense of self is also a feature of creative people. ... This identity diffusion or compartmentalized brain is caused by excessive local nerve connections and reduced long-range nerve connections. This leads to an unintegrated brain (Fitzgerald, 2014, p. 127).

Although the sense of self is weak in autism, autistic individuals turn much attention to themselves and often assume self-centered attitudes (Fitzgerald, 2014). The main objective of Saarikoski's youth diaries was to find his real self, which goal closely associated with his aspiration to become a poet. This was the quest for artistic identity and perfection. For him there was "a scientific interest with which I follow my development ... I am a problem in the first place to myself" (Saarikoski, 2012, p. 165). He was a keen self-observer as is common to autistic minds (Grandin, 2006). 
Saarikoski in his youth diaries often wrote about masks that he wears for different social occasions and reminded himself not to forget the search for the real self. In search for his identity Saarikoski could watch himself in mirror and practice acting for hours. He wrote that some of the masks he had created for himself have deeply grown into the skin of his face (Saarikoski, 2012). This means that certain self-induced social roles became compartments of his personal identity (Attwood, 2007). His identity diffusion manifested itself in very different roles that he could perform: "in my nature unite hermit and dandy, mocker and prophet" (Saarikoski, 2012, p. 66). One of his most prominent mask was that of a clown. According to Fitzgerald, autistic children often become "class clowns" which role gives them particular pleasure and the attention that they crave (Fitzgerald, 2018).

As an autistic person Saarikoski demanded honesty in his search for truth but noticed himself to be a social pretender. Saarikoski was cognizant of his identity diffusion and not happy with it: "I am too contradictory a human being, a complete enigma for myself as well as to others" (Saarikoski, 2012, p. 95). Occasionally he wrote with more self-confidence: "I love the chaos of my soul" (Saarikoski, 2012, p. 114). More often Saarikoski held his ego as sick and abnormal and complained about his childishness and immature nature. He wondered whether he would stay a child forever (Saarikoski, 2012). According to Fitzgerald, the great creators show a high level of curiosity during childhood and retain their immature personalities throughout their life. They see the world through the eyes of a child, which is important for great creativity (Fitzgerald, 2015). Saarikoski retained his childishness, he could not manage everyday life and lived only for poetry. According to his wife Tuula-Liina he lacked the social and practical skills that are self-evident in the general population (Varis, 1994). He never matured emotionally and therefore could get along with children very easily. He maintained a warm, sincere and respectful attitude in regard to children who also much loved him in turn. However, he was unable to function as the caregiver to his children (Varis, 1994).
People with autism frequently relate much better to children than to adults (Walker, \& Fitzgerald, 2006).

Saarikoski wrote in his youth diaries that he is the honest seeker of truth which he can only find within himself. In the final part of these diaries, he claimed success in finding his real self. He reported "a newborn's feeling of happiness" when he wrote on 23th of February 1956: "I am aware of my mission now, because I became aware of myself" (Saarikoski, 2012, p. 366). This is the testimony for development in Saarikoski's self-understanding, which took place at the age of 18 . However, frequent questioning about the self-identity did not cease in the diaries after that date. On March 10th, 1956, the poet explained his better self-knowledge with the visual insight that replaced his earlier conceptual and verbal approach:

No, I have not answered that question (i.e. about my real self) in any satisfying manner. But my relationship to myself has become so complicated that it is best for me to give up the attempt to chain my personality into the net of words. ... I have now a VISION about myself and I can express it only with the aid of poetic images (Saarikoski, 2012, p. 380).

The autistic persons are very often highly visual who think in pictures (Grandin, 2006). Saarikoski explained: "I don't think - I see" (2012, p. 261). He discovered around the age of 18-19 that he was the natural poet who could see his poems like in a dream. When writing a poem, every moment brought the new swirling images that could eventually obscure his sense of self completely. According to his new knowledge the truth can be captured in image, truth means seeing things in the right way (Saarikoski, 2012). In the end of this search period he declared self-knowledge as the poet: "I think that I have found myself. I know my job and I am aware of its difficulty. A man passes lightly if he can bear a burden" (Saarikoski, 2012, p. 498). He wrote that to conduct creative work is his only way to stay alive (Saarikoski, 2012). Finding his self was the 
momentous occasion in the life of young Saarikoski, when he became a poet.

Saarikoski's identity diffusion was also manifest in the easiness with which he embraced other identities. When he read Cervantes' novel Don Quixote he soon felt like a wandering knight himself and made compliments to his girlfriend in the congenial style. When he listened to the radio play Macbeth he suddenly sensed seeing Shakespeare and gradually turned into him (Saarikoski, 2012). When being unfaithful to his first wife, he identified with the Roman poet Catullus, who had behaved similarly (Tarkka, 1996).

The ability to pick up new identities did not disappear with age. When visiting Iceland, he craved to become an Icelandic nationalist. When reading the biography of the composer Sibelius, Saarikoski became Sibelius. His wife Tuula-Liina described: "He became somewhat majestic; he walked with dignity his brow furrowed, hands behind his back and gave orders to everybody." She asked him to stop the imitation of Sibelius. This comment amused the poet and he appreciated his wife's detecting of copying (Varis, 1994, p. 218). The camouflage and taking different roles also guided Saarikoski's social behavior. He had several roles in Finland, for which he was well known - the hero of restaurants, the mocker of bourgeoisie, bohemian, young genius, eccentric poet etc. (Tarkka, 1996). Contradictory identities can cause confusion in others. For a part of his life Saarikoski assumed the identity of a communist, although in his youth he explicitly rejected this ideology as "a dangerous religion" (Saarikoski, 2012, p. 442). This is another instance how rapidly a compartmentalized mind can switch between identities. Fitzgerald has pointed to similar multiplicity of identities and masks in the persona of the Irish poet W. B. Yeats (2005).

In his diaries Saarikoski once commented on the ancient Delphic maxim "Know thyself" writing that knowing is only possible when another character is allowed to enter the person but never otherwise (Saarikoski, 2012). T. Grandin has pointed to discrepancy between the thinking self and the acting self in autistic individuals (Grandin, \& Panek, 2013). This feeling of self-separation was a prominent feature in the personality of young Saarikoski. He wrote: "I'm monitoring my behavior all the time. I see myself as if being somewhere outside, as if I were some other human being, who is and is not me" (Saarikoski, 2012, p. 297). The seeming separation of mind and body is result of the lack of a fully integrated brain in autism, which can also bring about the feelings of isolation and exile (Walker, \& Fitzgerald, 2006). Saarikoski wrote: "My personality is simply not firm enough. I do not sense my actions as my own. I am a sort of test person" (Saarikoski, 2012, p. 502). Saarikoski's autism provides the explanation for such unusual sensations of self and body (Grandin, \& Panek, 2013).

\section{Saarikoski's Theory of Mind and Social Behavior}

Saarikoski's diaries offer many self-descriptions relating to his social behavior. He had social relationship problems which qualify as theory of mind deficiencies. Saarikoski stressed the importance of staying honest even at the cost of worsening interpersonal relationships (2012). Brutal honesty, the inability for diplomacy and white lies are characteristics of autism (Baron-Cohen, 2008). Saarikoski's relations with other people lacked reciprocity and cognitive empathy due to his ASC. His sister wrote in retrospect:

I admit that he was a prodigy and genius, but in one respect Penttis development remained at a childish and infantile level - in human relations. ... It was impossible for Pentti to understand that an interpersonal relationship is a mutual one and needs care - he was the one who needed the care! Can you always understand, forgive, forget, if in return you get indifference and distrustfulness? I understand well that Penttis intimates became tired (Garam, 1987, p. 116). 
In his diaries Saarikoski complained that he is as if forced to offend people whom he actually likes and friendships tend to break down (Saarikoski, 2012). $\mathrm{He}$ explained that "my coarseness and unpleasant arrogance are a cover" to protect his sensibility (Saarikoski, 2012, p. 76). Sometimes he speaks too much and gets too excited in social contexts so that he asked himself in diaries, "when will I learn to be silent and to listen?" (Saarikoski, 2012, p. 375). He gradually became more self-critical about his social deficiencies:

I am still not free of my sensuality, which I cover up with irony and insulting words. Do I ever become a decent social person? Earlier I imagined that the fault can be in the others; I gradually realized that it is within me, in my nature, which avoids any contact with the outside world. I want to live with myself and for myself (Saarikoski, 2012, p. 179).

The company of other people usually caused the young Saarikoski to be in a bad mood. He needed solitude to calm down. He admitted to being the self-centered person who cannot love anybody else but himself. The self-centredness is an autistic trait (Baron-Cohen, 2008). In solitude he discovered his inner world, but the fear of being deserted could ensue with the feeling of emptiness. He called his lifestyle "ascetic solitude" (Saarikoski, 2012, p. 136). Solitude is one of the most effective emotional restoratives for someone with autism and being alone can be a very effective way of calming down from anxiety (Attwood, 2007). Saarikoski could be verbally very harsh when his need for solitude was not met, which the following outburst in his diaries exemplifies:

Let me be alone. Why are you persecuting me, for what do you ask me? You people are thieves and murderers. With the smile of love and friendship on your lips you come to me - to kill me, to suck my power. Go away. Did I invite you? The white cloud of heaven is my friend, the cheerful mountain river my beloved, the sun my god what can you give me? The peace you carried away without giving me war. You are vultures, empty and soulless animals. Go, do not stop at the threshold, I meant what I said. I want to live and die alone, my only companions are a dream and a poem (Saarikoski, 2012, p. 182).

Saarikoski writes that he loses himself in the social company when adapting too easily to other people. He changes into a similar person with whom he is in contact - that he has "a face" to everybody and he can never enjoy being himself (Saarikoski, 2012). This facet of identity diffusion he had in common with W. B. Yeats, who "presented multiple faces to whoever he met" depending on the person and circumstances (Walker, \& Fitzgerald, 2006, p. 245). Saarikoski indicates his unusual eye contact with the following statement: "when I have a conversation I don't look at my partner, my eyes are drilled into the black cement floor as if to break it" (Saarikoski, 2012, p. 220). Saarikoski often failed to make an eye contact with his conversation partner, which is a trait of autism (Attwood, 2007).

For social situations Saarikoski learned to perform tens of roles. Much of Saarikoski's social behavior concealed the communication difficulties with the camouflage in which the person behaves as a natural actor using a script (Attwood, 2007). This is the autistic coping strategy, which may require considerable cognitive effort and can lead to increased stress, anxiety and depression (Lai, et al. 2016). As a well-known person in Finland many of these roles were familiar to the general public. His public image of the eccentric poet was well captured by a Finnish journalist after one cafeteria meeting in 1962:

It seemed that the restlessness of the whole world was centered on this one person who spoke quickly, spun his eyes, lifted his eyebrows, and peered back as if waiting for something. He was looking like he could suddenly rush up, turn over the table and chair and jump through the roof; he seemed to give a show rather than to relax (Tarkka, 1996, p. 510). 
Due to his ADHD traits and much energy Saarikoski was successful in acting out his characters that he did not naturally possess. However, this strategy had a cost. Most often he was able to face other people only under the influence of alcohol. When social anxiety increased Saarikoski could not leave home for several days often believing that he had committed embarrassing actions during his drinking bouts (Tarkka, 1996). His levels of social stress were overwhelming - he never appeared in public without using alcohol and many of his acquaintances and friends never saw him sober. Only among his immediate family he was able to relax and to talk a fair amount. Without the influence of alcohol he became extremely shy, a completely different person. For example, he could not answer to phone calls when home alone and unplugged the cable from the wall (Varis, 1994). His father had also been a very different person during his drinking bouts, which indicates inheritance of this trait (Garam, 1987). These enormous problems with social relations and understanding were rooted in Saarikoski's autistic traits.

\section{Saarikoski's relationship with women}

The young poet Saarikoski was an attractive person, who much liked to be in the company of women. According to some descriptions he had "enchanting eyes of a warlock" (Tarkka, 1996, p. 128). Fitzgerald points out that autistic gaze often has the "piercing eyes", which seem to look through people (Fitzgerald, 2014). His third wife, who met him first time in 1960 at a literary event describes her first impression of Saarikoski: "the head was large and round, somewhat heavy looking on the flimsy neck ... his voice was a bit tense and he was terribly serious" (Varis, 1994, p. 22). Macrocephaly is a physical trait of autism, which is due to accelerated brain growth in early development (Baron-Cohen, 2008). Many clinicians also refer to unusual pitch of voice in autistic individuals (Fitzgerald, 2018). During the brief meeting at the literary event Saarikoski impressed his future wife with seriousness and quietness (Varis, 1994). Selective mutism is a characteristic of autism (Attwood, 2007).

Saarikoski began to court his first wife Tuula Unkari at the regular youth events of their Christian congregation in 1952. The adolescent Saarikoski liked the girl but his shyness prevented him to approach her directly. $\mathrm{He}$ chose the stalking strategy that is common in autistic adolescents (Attwood, 2007). He followed the girl at the distance of about 10 metres and tried to hide himself every time she turned her head backwards. This approach irritated Tuula and after it had lasted for several weeks she insisted to Pentti either to walk beside her or to disappear. They started to walk side by side, but it took some more weeks before the boy became able to speak with her (Tarkka, 1996). This story exemplifies the unusual mating strategies that autistic people sometimes use with success.

During his life Saarikoski was married four times but none of these relationships lasted. His capacity to maintain intimate relationships was limited due to his autism. He confessed in his youth diaries that he does not understand the meaning of the word "love" and his relationships with other people are unstable (Saarikoski, 2012). The course of life events did not change this aspect of Saarikoski's personality. In the diaries that he wrote after moving to Sweden in 1975 he still complained about his inability to become attached and love the people close to him. He confessed that he is prone to closer emotional ties with birds and animals than with human beings (Garam, 1987). This proclivity is typical for autistic individuals (Grandin, 2006).

Due to his disinhibition problems Saarikoski was often unfaithful to his partners. As a famous person in Finland he had more than average opportunities to be unfaithful. The young Saarikoski seemed to forget all his romantic commitments in the company of beautiful women. He would like to kiss and embrace almost everybody (Saarikoski, 2012). During his first marriage he became concerned about the behavior pattern, which forced him to chase all the wonderful ladies he met. He was also prone to erotic adventures 
with persons of male gender (Saarikoski, 2015). In his moral consciousness he acquired the book Don Juan authored by the Spanish physician Gregorio Marañón, who wrote biological essays exploring human passions through historical characters. His motivation for reading the book was "to understand himself better" as he explained to his wife (Saarikoski, 2015, p. 53). However, from this book he only gained more selfconfidence. Saarikoski's promiscuous behaviors can be explained with his fragmented sense of self and identity diffusion, which are often found in creative individuals. The compartments or modules of the autistic brain communicate poorly with each other, which is the factor that leads to the identity diffusion (Fitzgerald, 2014). Diffuse self-identity may result in weak attachment to others who are close. For much of his life, Saarikoski also neglected his parents (Varis, 1994).

In Saarikoski's case the gender dysphoria or sexual identity diffusion is also found. Gender dysphoria is a frequent finding in people with autism (Fitzgerald, 2018). Saarikoski reveals his gender agnosia already in youth diaries when asking himself "Am I woman?" (Saarikoski, 2012, p. 80). This is the motif found also in his poetry, e.g. "I stand on the street and I don't know my gender" (Tarkka, 1996, p. 410). His third wife wrote that Saarikoski's character was quite feminine both as the poet and person. Saarikoski had dependency on women, was attached to them and appreciated them. He always had better contact with women than with men (Varis, 1994). Similar trust patterns can be found in many men with autism (Fitzgerald, 2005). In romantic relationships he was always the passive partner and behaved more like a typically female (Tarkka, 1996). The woman with whom he shared the home had to be secure like mother's lap (Varis, 1994).

His wife Tuula-Liina describes the sober periods of domesticity of the poet, which deeply shocked her in the beginning. The profound change in his persona took place, when all of a sudden the poet became very quiet, absent-minded and gave very short answers to questions. He sat all days at his table, stared out and wrote. The wife became suspicious of a relationship problem between them, but Pentti explained on the third day: "I am always like that when sober." He was silent, thinking, serious and infinitely hard-working with a fixed and slow gaze (Varis, 1994). Without stimulating substances he completely lost his socially active side, which happened at home.

Pentti Saarikoski was unable to deal with practical matters due to his ADHD and autistic traits. He needed someone to give him clean clothes, he did not know where the things were in their home. He had no understanding of money. He was not capable of longterm planning. Only his working desk and his books on shelves were always in a perfect and pedantic order (Varis, 1994). For Saarikoski his work was the highest priority before family life. However, it was "so strangely easy" to be with him (Varis, 1994, p. 49). He was the honest person who always spoke his mind. He could not keep domestic and personal secrets from others and sometimes revealed them inappropriately. These theory of mind particularities are common in people within the broader autism phenotype (Fitzgerald, 2018).

Due to his autism Saarikoski did not cope with unexpected changes. There are many examples of his temper tantrums. He fell into long and reckless drinking periods after every divorce. The closure of his favorite restaurant Hansa where he used to work in Helsinki was a serious blow for him. The housing change soon followed, which caused the heightened stress that eventually led to the divorce from his third wife (Varis, 1994). His relationship status was rescued with a happy accident when the Norwegian sociologist Mia Berner came to Helsinki to interview him. She had fallen in love with him after seeing his photo in a bookshop window. She took Saarikoski with her to Sweden where he spent the rest of his life since 1975 (Berner, 1986). 


\section{Pentti Saarikoski's Literary Style}

Pentti Saarikoski was an autistic poet, who visualized his texts that he composed. He wrote approximately 20 collections of poetry. He was able to write always and everywhere (Varis, 1994). He kept notebooks where he wrote down everything important that crossed his mind (Tarkka, 1996). This is common to creative persons with autism (Fitzgerald, 2014). The poems represent his experiences of the world as he explained in diaries: "I express myself through images ... objects and things are more important for me than their essence or meaning" (Saarikoski, 2012, p. 374). According to his wife TuulaLiina he used no hidden symbolism behind his poetic images, the poems always exactly mean what they say (Varis, 1994). For Saarikoski's poems the experiences expressed are more important than general semantics and symbolism. Saarikoski's editing of his texts was meticulous about details and laborious.

Penttis way of making his own text ... seems sometimes easy but more often it is difficult, distressing and at some stages agonizingly monotonous. He is pedantic, he studies spaces for commas, he grinds and planes. ... Even a typo in the text will force him to squeeze the paper out of the machine and rewrite the entire page (Varis, 1994, p. 105).

This level of detail focus is a characteristic of ASC (Baron-Cohen, 2008). Most of Saarikoski's literary production was poetry, but he also published the collection of satirical essays The Nose's Columns (1960) and a couple of works in prose. However, the prose books he wrote were not novels but the series of everyday sketches in the travel accounts like The Time in Prague (1967) and The Edge of Europe (1982). Saarikoski was an empirical writer like James Joyce, who recorded the environment and facts of human nature with great precision and detail. The capacity of autistic authors to write novels may be limited due to their weak central coherence (Roth, 2008). The autistic narrative can be a fragmented discourse with lack of coherence. Autistic writers may have little capacity for plotting. Nevertheless the genre of novel requires a sustained development of ideas. Therefore the novels that James Joyce authored are strikingly plotless, hanging together with a structured approach (Walker, \& Fitzgerald, 2006). The same applies to Saarikoski's prose works, which are the plotless narratives and diaries describing certain environments and events. In the letter to his sister from February 2nd, 1979, he described his relationship to writing in prose as follows:

I cannot write novels or short stories because I am not able to imagine. For me people are without history who walk in space, the creatures making body movements and gestures that cease to exist when they are no longer visible to me. This is not to be understood as a hatred against humanity, I mean just my manner of writing (Garam, 1987, p. 163).

Saarikoski reveals here his behavioristic understanding of human characters that is typically autistic (BaronCohen, 1989). He had little talent for imagining minds and histories of individuals. He possessed limited social and interpersonal imagination, but enormous autistic imagination (Fitzgerald, 2014). The cognitive capacities for writing prose such as sustaining control over the continuity and unity of narrative can be impaired in people with autism. They have cognitive processing bias toward parts rather than wholes, which makes writing of a novel difficult. Saarikoski's autistic cognition was more appropriate for writing poetry, where the fragmentation of language and images can have positive impact adding to its appeal. The ability to leap from one idea to another conveys more attraction to poetic language, which becomes tantalizing and intriguing for readers (Roth, 2008).

Saarikoski was a hyperkinetic type of a creative person - the autistic wanderer as described by Fitzgerald (2015). His favorite literary character was that of the wandering Odysseus, who escapes from home and searches for home at the same time. This contradiction 
is essentially autistic. Saarikoski often made journeys to different places in Europe to concentrate on certain works. He travelled to Dublin, where he wrote The Letter to my Wife (1968), which describes his loneliness. His home during these travels was his native tongue, the tool to produce literature and to counteract his sense of alienation and loneliness. He nevertheless needed these feelings to be able to write. He was more comfortable abroad, where his autistic sense of being a stranger more precisely matched the actual situation. As the outsider he did not need to deal with things that disturbed his concentration at home (Varis, 1994). This behavior of wandering is conditioned by autistic novelty seeking (Fitzgerald, 2015).

His wife Tuula-Liina remembered from their common journeys that Saarikoski had the uncanny ability to absorb himself into the atmosphere of a foreign city in few days and then to behave and live there like a local resident. The faculty to pick up new identities in novel places was due to his identity diffusion and flexible mind. While abroad he was more relaxed and consumed less alcohol. He did not need not to perform his stressful roles as in Finland (Varis, 1994). He used his hypersensitivity to describe the new environments with great precision in his prose works. His wife commented on the book he wrote in Prague, 1967 as follows:

\begin{abstract}
He seems to hear, see and sense so much ... nobody has perceived the seemingly stagnant but under the surface restless time of Novotny before the Prague spring in the same way as Pentti did in his work The Time in Prague (Varis, 1994, p. 106).
\end{abstract}

Fitzgerald (2014) writes that persons with autistic brains perceive a huge amount of raw details without the higher meaning and possess a heightened sensitivity to parts without recognizing the whole. Concept formation is impaired in autistic minds (Snyder, Bossomaier, \& Mitchell, 2004). Autistic individuals have less mental models or conceptions and therefore they can be more aware of novelty. Persons with autism have "continuous infantile awareness of raw sensory data which produces a vastly increased number of conscious sensations" (Fitzgerald, 2014, p. 9). The strength of autistic creativity lies in the persistent ability to experience the world and oneself with fresh details and novelty (Fitzgerald, 2014). Persons with autism can be less prone to dogmatism and less dependent on current theories, which gives them the better position to move towards new methods and theories. They may achieve the ability to use this autistic creativity mechanism and produce literature in which novel sensations abound. This well applies to Pentti Saarikoski, who established new forms in Finnish literature by writing original poetry. ASC and ADHD traits enhanced his creativity but made his everyday life difficult in many respects.

\section{Conclusion}

The Finnish poet Saarikoski well conforms to the description of highly creative persons having elevated levels of ASC and ADHD traits (Fitzgerald, 2008; 2015). Creativity of genius proportions can be found in the combination of high intelligence and autistic traits (Fitzgerald, 2011). These criteria well apply to Saarikoski. The paradox of persons like Pentti Saarikoski, who have extremely high intelligence but also substance abuse problems can be assessed with the reference to heightened anxiety and novelty seeking that arise from the combination of ASC and ADHD traits. Genetics will eventually provide the final answer to the question about the relationship between various forms of psychopathology and high creativity. However, elevated risk for ASC and ADHD traits is expected to figure in the genotypic data of many highly creative persons.

\section{Acknowledgements}

Work on this paper was supported by a personal research grant from the Estonian Research Council (PUT 1466). The author is grateful to Christopher Badcock for discussion. 


\section{References}

Attwood, T. (2007). The Complete Guide to Asperger's Syndrome. London, Philadelphia: Jessica Kingsley Publishers.

Baron-Cohen, S. (1989). Are autistic children "behaviorists"? An examination of their mentalphysical and appearance-reality distinctions. Journal of Autism and Developmental Disorders, 19(4), 579-600.

Baron-Cohen, S. (2008). Autism and Asperger Syndrome. The Facts. Oxford: Oxford University Press.

Beaussart, M. L., White, A. E., Pullaro, A., \& Kaufman, J. C. (2014). Reviewing recent empirical findings on creativity and mental illness. In: Kaufman, James C. (ed.) Creativity and Mental Illness, pp. 42-59. Cambridge: Cambridge University Press.

Becker, G. (2001). The association of creativity and psychopathology: Its cultural-historical origins. Creativity Research Journal, 13(1), 45-53.

Berner, M. (1986). PS merkintöjä suruvuodelta - Pentt Saarikoski. Helsinki: Tammi.

Butwicka, A., Långström, N., Larsson, H., Lundström, S.; Serlachius, E., Almqvist, C., Frisén, L., \& Lichtenstein, P. (2017). Increased Risk for Substance Use-Related Problems in Autism Spectrum Disorders: A Population-Based Cohort Study. Journal of Autism and Developmental Disorders, 47, 80-89.

Dollinger, S. J., Urban, K. K., \& James, T. A. (2004). Creativity and openness: Further validation of two creative product measures. Creativity Research Journal, 16(1), 35-47.

Fitzgerald, M. (2005). The Genesis of Artistic Creativity: Asperger's Syndrome and the Arts. London, Philadelphia: Jessica Kingsley Publications.

Fitzgerald, M. (2008). Attention Deficit Hyperactivity Disorder: Creativity, Novelty Seeking and Risk. New York: Nova Science Publishers.

Fitzgerald, M. (2011). Creativity, Psychosis, Autism and the Social Brain. A Comprehensive Book on Autism Spectrum Disorders, Dr. Mohammad-
Reza Mohammadi (Ed.), ISBN: 978-953-307-494-

8, InTech. DOI: 10.5772/17439

Fitzgerald, M. (2014). The Link Between Asperger Syndrome and Scientific, Artistic, and Political Creativity: Eleven Case Studies. Lewiston, Lampeter: The Edwin Mellen Press.

Fitzgerald, M. (2015). The Mind of the Artist. Attention Deficit Hyperactivity Disorder, Autism, Asperger Syndrome and Depression. New York: Nova Science Publishers.

Fitzgerald, M. (2018). The broader Autism Phenotype: expanding the Clinical Gestalt of Autism and broadening DSM V criteria of Autism Spectrum Disorder. Journal of Psychology and Clinical Psychiatry 9 (3): 316-324.

Garam, S. (1987). Veljeni Pentti: Pentti Saarikoski sisaren silmin. Helsinki: Kirjapaja.

Grandin, T. (2006). Thinking in Pictures: My Life with Autism. New York: Vintage Books.

Grandin, T., \& Panek, R. (2013). The Autistic Brain: Thinking across the Spectrum. Houghton Mifflin Harcourt.

Lai, M.-C., Lombardo, M. V., Ruigrok, A. N. V., Chakrabarti, B., Auyeung, B., Szatmari, P., Happé, F., Baron-Cohen, S., \& MRC AIMS Consortium (2016). Quantifying and exploring camouflaging in men and women with autism. Autism. DOI: $10.1177 / 1362361316671012$.

Nieminen-von Wendt, T. (2004). On the Origins and Diagnosis of Asperger Syndrome: A Clinical, Neuroimaging and Genetic Study. University of Helsinki Dissertation. Helsinki: Yliopistopaino.

Rommelse, N. N., Franke, B., Geurts, H. M., Hartman, C. A., \& Buitelaar, J. K. (2010). Shared heritability of attention-deficit/hyperactivity disorder and autism spectrum disorder. European Child \& Adolescent Psychiatry, 19(3), 281-295.

Roth I. (2008). Imagination and the Awareness of Self in Autistic Spectrum Poets. In: Osteen, M. (ed.) Autism and Representation, pp. 145-165. New York: Routledge.

Saarikoski, Pentti (2012). Nuoruuden päiväkirjat. 4th Edition. Helsinki: Otava. 
Saarikoski, Tuula (2015). Kaaos ja kirkkaus: muistelmat. Helsinki: WSOY.

Schuldberg, D. (2001). Creativity and psychopathology: Categories, dimensions, and dynamics. Creativity Research Journal, 13(1), 105-110.

Simonton, D. K. (2014). The mad (creative) genius: what do we know after a century of historiometric research? In: Kaufman, James C. (ed.) Creativity and Mental Illness, pp. 25-41. Cambridge: Cambridge University Press.

Snyder, A., Bossomaier, T., \& Mitchell, D. J.

(2004). Concept formation: 'object' attributes dynamically inhibited from conscious awareness. Journal of Integrative Neuroscience, 3(1), 31-46.
Tarkka, P. (1996). Pentti Saarikoski, vuodet 1937-1963. Helsinki: Otava.

Tarkka, P. (2003). Pentti Saarikoski, vuodet 1964-1983. Helsinki: Otava.

Varis, T.-L. (1994). Kilpikonna ja olkimarsalkka. Porvoo, Helsinki, Juva: Werner Söderström OY.

Walker, A., \& Fitzgerald, M. (2006). Unstoppable Brilliance: Irish Geniuses and Asperger's Syndrome. Dublin: Liberties Press.

Warrier, V. (2018). The Genetics of Autism and Related Traits. Doctoral dissertation. Autism Research Centre. University of Cambridge.

Willer, J. (2017). Could it be Adult ADHD? A

Clinician's Guide to Recognition, Assessment, and Treatment. Oxford, UK: Oxford University Press. 